\title{
Providing a Complete Menu: Using Competitive Usability in a Home Page
}

\section{Usability Study}

\section{INTRODUCTION}

The Web team at the University of North Texas (UNT) Libraries decided that a redesign of the Web site was needed because the current site has been in place for three years. As an initial step, we decided to perform a base-line study to first determine what users appreciated or disliked about the current site. To gain a complete awareness of the preferences of our users, we decided to test several other home pages that were very different from ours. Nielsen and Curtis (1995) stated that "The best prototype for designing your new user interface is your old user interface. The second best prototype is a competing product" (p. 75). They added that the most effective time to do this is before the initiation of a redesign so that the data can be incorporated into the new prototypes. Using "competitors" pages in usability studies is referred to as "competitive usability."

The complete study used formal usability studies or task-based testing (referred to as formal usability studies for the purposes of this paper), card sorts, and focus groups. This paper will deal only with the results of the formal usability studies and focus groups because these techniques involved other libraries' Web pages, while the card sort focused solely on the UNT Libraries' home page.

\section{LITERATURE REVIEW}

A review of the literature offered no library-related competitive usability studies, but several studies have evaluated multiple home pages for various characteristics. Johnson (1997) looked at the home pages of 31 academic 
libraries to critique their design, appeal, originality, and usefulness. The quality of 60 library home pages and 50 company homepages were reviewed for content, currency, graphics, clarity, and overall service (Wille, 1998). One hundred and forty-three academic home pages and their respective library home pages were examined by Bao (2000) to determine what percentage of libraries had direct links off the organization's home pages and what percentage of the libraries' home pages had links to online databases. Wright (2004) reported on 114 academic library pages in relation to their provision of Internet search engine and Web site evaluation information.

A number of studies have examined multiple library Web pages for accessibility. Examples include Lilly and Van Fleet $(1999,2000)$, Schmetzke (2000), and Spindler (2002). These studies used Bobby and several manual checks to determine the level of accessibility on the pages. Bobby is a free software program that checks web pages for accessibility errors to bring them into compliance with current accessibility guidelines. More information on Bobby can be found at http://bobby.watchfire.com/bobby/html/en/index.jsp.

Competitive usability studies are increasingly common in the business world. Nielsen and Curtis (1995) reported on a study that employed 4 home pages of businesses to determine which features users preferred. Johnson (1996) provided a review of government Web pages and offered some design suggestions. Agarwal and Venkatesh (2002) discussed a study which examined multiple business Web sites from airlines, online bookstores, automobile 
manufacturers, and car rental agencies. They had nearly 1500 participants examine the Web sites using a set of well-defined heuristics.

Many books and articles effectively outline Web site usability and Web site usability studies. Recommended examples include Rubin (1994), Campbell (2001), and Norlin and Winters (2002). Thompson (2003) presented an interesting article which emphasizes the possible differences between usability and "usefulness." Rosen, et al. (2004), provided a look at usability from a cognitive psychology perspective noting that "By identifying the end users' preference patterns, environments could be designed that make it easier for people to feel comfortable entering a landscape because they believe that they will be able to function effectively once they actually enter the landscape" (p. 17). In essence, they support the importance of usability - focusing on the users rather than the "experts." Previous articles by the author (Thomsett-Scott 2004a, 2004b, 2004c) present details on the techniques used in the formal usability studies and focus groups as employed in this study.

\section{Materials and Methods}

\section{Home Pages}

The three competitor homepages were chosen based on differences in their design and functionality from the UNT Libraries' home page. The University of Arizona (UA) Library page was included because its design is based on the results of usability studies (see Dickstein \& Mills, 2000, as an example). Due to its broad spectrum of choices, the University of Waterloo (UW) Library's page was chosen. Oklahoma State University (OSU) Library's page (OS) was selected 
since a previous study by the author had indicated that students wanted to see drop-down boxes on the home page (unpublished results). All pages are shown in the results section with student preferences indicated.

\section{Participants}

Ten undergraduate students, 10 graduate students, and 10 students with distance education experience ( 5 undergraduates and 5 graduate students) were hired for the study. An even distribution of gender and English as a second language (ESL) was attempted, and a wide assortment of disciplines and races were selected. Demographic details and satisfaction information with the UNT page was collected at the end of the task-based testing portion of the study.

\section{Formal Usability Studies}

Students were asked to perform formal usability studies on the home pages as the initial phase. Participants were asked ten questions developed from common items on the pages, such as the catalog, databases, subject guides, and virtual reference services.

The questions were beta-tested and small wording changes were made as necessary. During the sessions, however, several questions required the use of a standardized prompt.

Participants were brought in individually for the studies. Two-thirds of the sessions had a moderator and recorder/timer, while the others had the moderator performing all the functions. The success rate, time taken, and pathways were recorded. Video capture software was used to assist in the pathway recording. 
Home pages were presented in random order. Each page was presented in each spot (first, second, third and fourth) approximately the same number of times. All ten questions were completed on one site before moving on to the next site. Participants were given a maximum of three minutes to correctly answer each question on each home page. Nielsen and Curtis (1995) support showing each user each page rather than showing individual pages; in "competitive usability" testing, the other pages are not being redesigned and the concern over "transfer of learning" is minimized, especially since the pages were chosen based on their differences, including terminology, from the UNT's page. More details on the procedure can be found in Thomsett-Scott (2004a and 2004b).

\section{Focus Groups}

When all of the participants had completed the formal usability studies, they returned for focus groups in groups of approximately five and, as much as possible, in their category (undergraduate, graduates or online learner). Online learners were not divided into undergraduate and graduate levels due to scheduling issues. Participants were asked 7 questions involving their likes and dislikes of each site, elements that were easy or difficult to use, and features or elements of other pages from their own experiences.

The focus groups were held in the same room as the formal usability studies which, while fairly small, provided better results than focus groups held in a bigger room (see Thomsett-Scott 2004a for a more complete discussion of this phenomenon). 
Each focus group participant was provided with extra paper and matching pens to record comments hat they did not feel comfortable sharing with the group or that they did not have enough time to discuss. Several participants included valuable suggestions on the comment sheets. Additional discussion on the operation of the focus groups is provided in Thomsett-Scott 2004c. Screen shots of the home and major secondary pages were available during the discussions.

Discussions began with UNT's page, then UA's page, followed by UW's and then OSU's pages. The University of Guelph Library's page (www.lib.uoguelph.ca which has recently be redesigned), LL Bean's main page (www.llbean.com) and Amazon.com's home page (www.amazon.com) were also provided in the package of screenshots because they had elements and features that the moderator thought might enhance the discussions. Participants were able to discuss other pages from their own experiences that had design characteristics or elements that would be beneficial to the redesign of UNT Libraries' home page.

\section{RESULTS AND DISCUSSION}

The home pages are shown with many of the participants' preferences indicated. The University of North Texas Libraries is shown in Figure 1. Figure 2 shows the University of Arizona Library's home page. The University of Waterloo Library's page is presented in Figure 3. Oklahoma State University Library's page is offered in Figure 4. Since the page required scrolling, two screen shots are presented to show the desired features.

\section{Formal Usability Studies}


Only a few participants had used UNT's site extensively, so it was a "new" site for them. The other library sites were unknown to the participants. Two pages (UA and UW) compared to UNT's generally performed better in terms of success rate and time taken, except when the answer was well hidden on the sites.

Verbal and non-verbal cues indicated higher satisfaction with the other two sites, due to the increased ease of use and higher success rates. Despite incorporating three other pages into an otherwise traditional usability study, participants completed the formal usability studies in less than two hours. There was no indication of increased frustration or tiredness on the part of the participants. Some participants actively discussed their likes and dislikes of the sites during the debriefing sessions, although this was not asked of them.

\section{Focus Groups}

Comments are presented by broad category or specific element. Responses are derived from individual statements, not necessarily from distinct participants. That is, one participant may have mentioned a similar comment more than once.

\section{a) General Layout}

Despite UNT's page initially receiving high marks for overall appearance as evidenced by ten comments on the benefits of the simple design, there were six comments about too much white space. Sixteen participants warned against overcrowding (no specific page mentioned), and all participants desired "effective" use of white space. Similar comments were made by participants in Thomsett-Scott (2004c). Another six comments warned against making people 
scroll, although participant response to these were mixed. One participant noted that "if there is useful information below, students don't mind scrolling."

[place Figure 1 here]

Although the focus of this paper is on the home page, it is worthwhile noting that five participants made comments that UNT's and UA's secondary pages were too "texty" and/or too "busy." The comments were unfortunately not more specific.

\section{b) Branding and Contacting}

Branding and contacting comments issues were raised. Seven comments focused on the necessity of keeping a consistent look. Participants want to know when they are on the same site and when they have left the Library's site. Five participants wanted contact information, such as the physical address and phone numbers, on the home page. Two participants spoke against contact information as long as there was an adequate link elsewhere on the page.

\section{c) Elements}

There were 31 comments for the desirability of icons. It must be noted that many of these comments included an adjective such as "professional-looking." Six participants noted the necessity of the icons being "meaningful" to users. Nearly all ESL participants preferred icons to links. One participant noted that he preferred icons to links because his feelings were "less hurt" if he clicked on an incorrect icon than if he clicked on an incorrect link.

Drop-down menus, such as those on UW's page, received 47 positive comments. Participants preferred drop-down menus as they could rapidly see all 
the (main) options available to them. There were 5 comments on the need for a secondary page behind each drop down.

[place Figure 2 here]

There were 16 comments on the usefulness of the mouse-overs used on UNT Libraries' home page. Mouse-overs provide information on what participants could find behind the links. Since drop down menus can provide more options, these were preferred. Several participants thought that the mouse-over text was too small.

There were 12 comments relating to personalization (MyLibrary, MyYahoo, etc.). Seven participants wanted a system that would send them book recommendations or allow a "what I read" idea. Receiving alerts for new books that matched their search terms was suggested 6 times.

Eight participants noted that a consistent side navigation bar, such as on UNT's secondary pages, was a useful element. Seven participants recommended ensuring that the side navigation bar moves down when scrolling so it is always available.

Six participants commented on the usefulness of "breadcrumbs" that provide an effective means of navigation. The need for a search box received 10 comments, and 4 comments emphasized the desirability of a good site map.

The quick links feature, found on all four sites although in different formats, received high praise from 13 participants. There were 6 comments on the completeness of UA's quick links and 3 for the usefulness of UW's 4 buttons on the right side of the screen, and 2 positives for the selection of UNT's quick links. 
[place Figure 3 here]

\section{d) Desired Links}

The direct catalog link shown on UW's page received 23 comments on its desirability for UNT Libraries' revised page. Participants considered this to be a welcome time-saver for quick look-ups such as specific titles and reserve materials.

There were 21 comments on the importance of having a link to the hours prominently displayed on the home page. This is one example where OSU's page was mentioned as being "useful" for students because it had a number of desired links.

[place Figure 4 here]

There were fifteen comments on the need for "electronic resources", such as databases and online reference materials, and related information to be directly accessible of the home page. Five comments were received on the difficulty of distinguishing between journal articles and e-journals.

Eighteen comments focused on the desirability to having a link to "library news", including promoting new products or resources that students need to use at particular times of the year. For example, one student mentioned that a link to online style manuals and writing guides should be on the home page when students are most actively involved with writing term papers. Several students noted that links to tax forms and tax information should be offered during tax season. Three participants noted that they would prefer a few items of news rather than just a link. 
The importance of having a direct link to "my library account" was emphasized by 17 participants. As with the direct catalog link, participants desired quick access to important or commonly used information.

Although all pages had some form of help link, participants overwhelmingly preferred UW's terminology of "Research Starting Points", while 15 comments discussed the importance of this link being prominently displayed on the home page. Participants appreciated having essential resources grouped together.

The preference for a direct link to any form of virtual reference was noted by 13 participants. Thomsett-Scott (2004c) reported on a study where participants provided their ideas on the marketing and promotion of virtual reference, and the importance of having the virtual reference link on the home page was highly desired.

After noting Arizona's database multi-search capabilities, 13 participants endorsed this element for UNT's page, although they added that it must work efficiently. Thirteen comments were also received for the need for a quick links area on the home page, as mentioned previously.

Nine participants noted that having job openings on the home page when jobs were available was helpful. This item, along with several others mentioned below, indicate a participant preference for having the home page provide timely information.

Six participants stated that there should be a link on the home page that provides information on computer labs, and that subsequent pages should provide details for each lab on equipment available, such as scanners, software, 
and so on. Access to information that will aid in their scholarship was vital for the participants.

The importance of having some form of help or assistance on the home page (other than virtual reference) was emphasized by 5 participants. Participants agreed that the help links should be brought together into one link to preserve valuable space on the home page.

Providing information for specific groups, such as shown on UW's page, received 5 comments. Five participants requested easy access to the new book list.

A direct link to the course reserves area was mentioned by 4 participants, and 4 desired a direct "renew books" link to be on the home page, such as UW's drop-down menus provide. Subject guides (or similar) were suggested by four people as being essential links on the home page, although several more mentioned them as being very useful in the formal usability study.

Information on important academic calendar events, such as the last day to drop courses, was suggested by three participants. Three people suggested a link to campus events.

Two participants mentioned the benefit of drawing online forms together, as UW's drop down menus do. Despite its low comment rate, the moderator and observers noted that it was an enormous benefit, and a highly satisfying feature, during the formal usability studies.

A number of items received only one or two suggestions but are worth noting. There were 2 requests for links to online newspapers, 2 suggestions for Web 
access statistics (how often pages were accessed, similar to log files), 1 suggestion for current news, 1 request for the date, 1 request for the New York Times Book Reviews, and 1 comment for an frequently asked questions file.

\section{Pros and Cons of Competitive Usability}

Employing competitive usability in a baseline usability study (gathering data on a current page or site) is highly recommended. The difficulties encountered were just slight exaggerations of any usability study, such as the amount of time needed for the studies and difficulties in getting participants scheduled. Despite adding 3 additional pages to the study, both the focus groups and formal usability studies were able to be completed in two hour blocks. An added difficulty of competitive usability is the number of paths to an answer that might exist and with the researchers not being familiar with the other sites which increases the difficulty of tracking the participants' pathways taken to answer the questions. On UNT's pages, the researcher recording the pathway could put the first word in the title of the page for the path, but the pages on the other sites required more details. A video capture software is strongly recommended when testing other libraries' home pages. Additional time is necessary to review and analyze the videos.

Unforeseen issues included site down time and site redesign during the test. One site was down for several days, and three participants had to be rescheduled for their formal usability study slots. In the middle of the focus groups, one site revealed a new design. Luckily, screen shots of the old site had 
been captured. It is recommended to contact the webmaster of the other test sites in determine the efficacy of using the site in a usability study.

The usual concerns with usability testing still hold true. There is participant and staff bias towards a "look" rather than "usability." Staff will frequently prefer the current design rather than embrace change, and the results of the studies may not be well accepted. These issues can be reduced by including staff as volunteers and using video capture software as well as videotaping the sessions. Involving staff or providing pictorial evidence will assist in reducing the resistance to change.

Despite some new problems and possible exacerbation of old issues, it is well worthwhile to use competitive usability. When presented with other pages, users can compare and contrast the pages rather than simply commenting on one page. This may increase the effectiveness of any redesign by pointing out elements and design features that may not have been considered otherwise. The design elements and functionality that are discussed with the participants are not limited to skills and technology within the organization but include other options, although new skills and technology may be needed to include them on the home site.

Examining other Web pages may also help to avoid previously unobserved flaws, such as the effects of excessive drop downs or hidden buttons, and the value of various design elements, such as icons. By incorporating other pages in this study, it was determined that too many drop-down boxes are not favored, while one drop-down box that gathers together a lot of essential information and 
provides rapid access to this information, such as the drop down on AU's page, may be useful, depending on the rest of the page design. Nielsen and Curtis (1995) noted that evaluating other products is an effective way to test what works and what doesn't work for a particular set of users.

Of course, the major benefit of usability studies that include techniques involving real live users is that there will be actual user data and comments to support your ideas and contribute to knowledge of best practices for your own users.

\section{CONCLUSIONS}

The results of the formal usability studies and focus groups clearly indicate that the participants want quick access to important information and resources. Items such as a direct link to the catalog (catalog search box), "Research Starting Points", and frequently used resources at important times, such as style manuals and tax forms, are highly valued. Elements that provide quick access, such as drop down-menus and icons, are desired by users.

The usability process was enhanced by performing competitive usability on other academic library home pages. The satisfaction of the participants in being able to discuss other web pages or elements from their experience was quite noticeable. Aside from some extra test time and analysis time, there were no drawbacks to this process. The benefits derived far outweigh the extra time needed. Competitive usability is an effective component of Web site usability studies.

Author's Notes: 
The author would like to thank the American Library Association Poster Session Committee for providing an opportunity to display initial results from this study. As well, the author would like to express her gratitude to her colleagues at the University of North Texas Libraries who assisted with the study. 


\section{REFERENCES}

Agarwal, Rita, and Viswanath Venkatesh. "Assessing a Firm's Web Presence: A Heuristic Evaluation Procedure for the Measurement of Usability." Information Systems Research 13, no. 2, (2002):168-186.

Bao, Xue-Ming. "Academic Library Home Pages: Link Location and Database Provision." Journal of Academic Librarianship 26, no. 3 (2000): 191-195.

Campbell, Nicole. 2001. Usability Assessment of Library-Related Web Sites. Chicago, IL : Library and Information Technology Association.

Dickstein, Ruth and V. Mills. "Usability Testing at the University of Arizona Library: How to Let Users in on the Design". Information Technology and Libraries 19, no. 3 (2000): 144-151.

Johnson, Edith. "Government Web Pages: The Lights are on But Nobody is Home." Electronic Library 14, no. 2 (1996): 149-156.

Johnson, Steve. "Library Acquisition Pages on the World Wide Web." Library Acquisitions: Practice and Theory 21, no. 2 (1997): 195-204.

Lilly, Erica B., and Connie Van Fleet. "Wired But Not Connected: Accessibility of Academic Library Home Pages". The Reference Librarian 34, no. 67/68 (1999): 5-28.

Lilly, Erica B., and Connie Van Fleet. "Measuring the Accessibility of Public Library home Pages." Reference and User Services Quarterly 40 (2000): 156163.

Nielsen, Jakob, and Bill Curtis. "A Home-Page Overhaul Using Other Web Sites." IEEE Software 12, no. 2 (1995): 75-78.

Norlin, Elaina and CM! Winters. 2002. Usability Testing for Library Web Sites. Chicago, IL. : American Library Association.

Rubin, Jeffrey. 1994. The Handbook of Usability Testing: How to Plan, Design and Conduct Effective Tests. New York, NY : Wiley.

Schmetzke, Axel. "Web Page Accessibility at 24 U.S. Universities : 2000 Survey Data, July 20, 2000." Accessed November 2, 2004, ibrary.uwsp.edu/aschmetz/Accessible/nationwide/Survey2000/contents2000.htm 
Spindler, Tim. "The Accessibility of Web Pages for Mid-Sized College and University Libraries." Reference and User Services Quarterly 42, no. 2 (2002): 149-154.

Thompson, Stephen. "Web Site Usability vs Usefulness". B to B 88, no. 9, (2003):9-11.

Thomsett-Scott, Beth. Turning Students On To Your Web Site Using Usability Testing. In Proceedings of the Victorian Automation and Library Association 12th Biennial Conference and Exhibition. Located online at:

http://www.vala.org.au/vala2004/2004pdfs/72Thomst.PDF (mounted January 2004), 2004a.

Thomsett-Scott, Beth. "Yeah, I Found It!: Performing Web Site Usability Testing to Ensure That Off-Campus Student Can Find the Information They Need". In Proceedings of the Eleventh Off-Campus Library Services Conference, edited by Patrick Mahoney. Mount Pleasant, Mich. : Central Michigan University, (2004b):355-364.

Thomsett-Scott, Beth. "If You Ask, I Will Tell You: Future Users of Virtual Reference Share Their Thoughts on the Design, Operation, and Marketing of Virtual Reference". In The Virtual Reference Experience: Integrating Theory into Practice, edited by R. David Lankes, Joseph Janes, Linda C. Smith, and Christina M. Finneran. New York, NY : Neal-Schuman, (2004c):63-86.

Wille, P. "A Comparison of the Internet Presence of German Libraries and Companies." Libri 48, no. 4 (1998):224-236.

Wright, Carol A. "The Academic Library as a Gateway to the Internet: An Analysis of the Extent and Nature of Search Engine Access from Academic Library Home Pages". College and Research Libraries 65, no. 4 (2004): 276-287. 


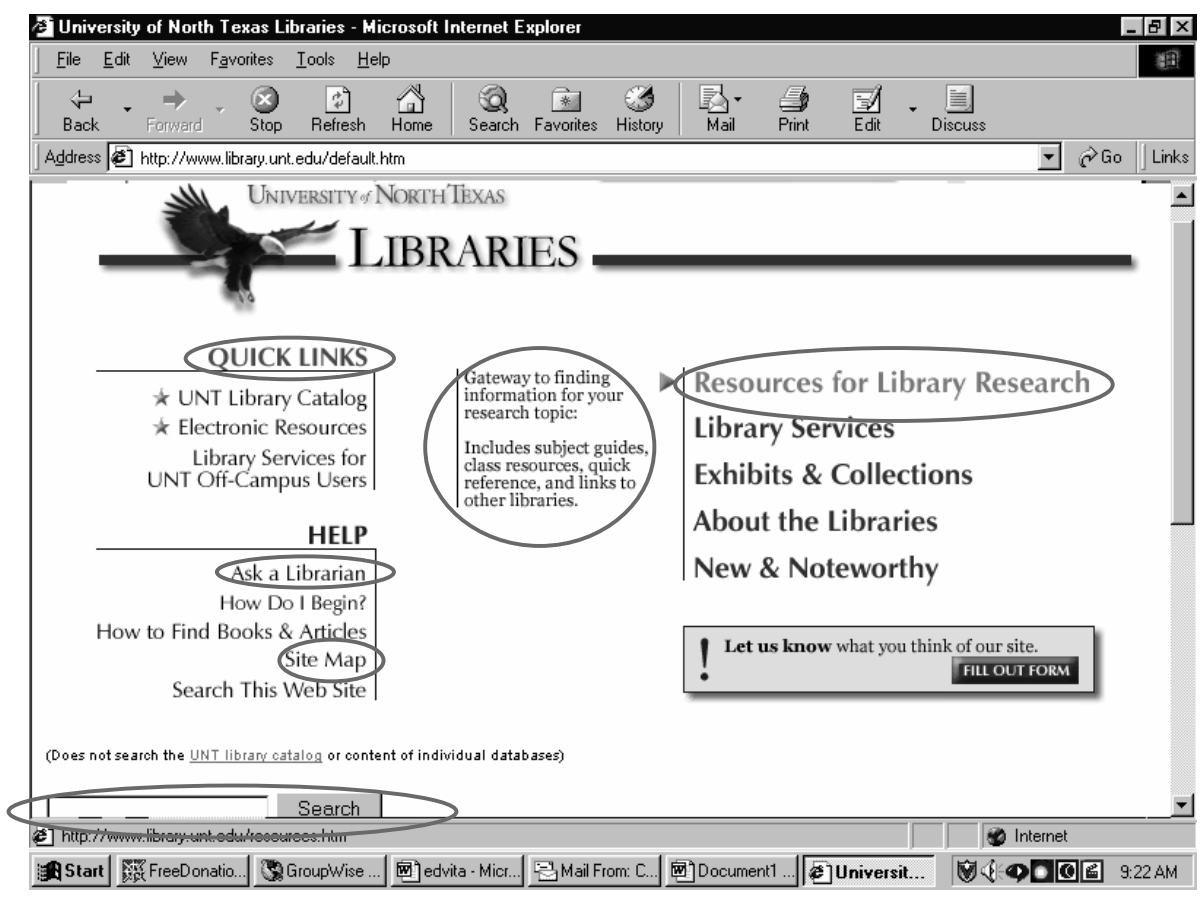

Figure 1: The University of North Texas Libraries' home page 


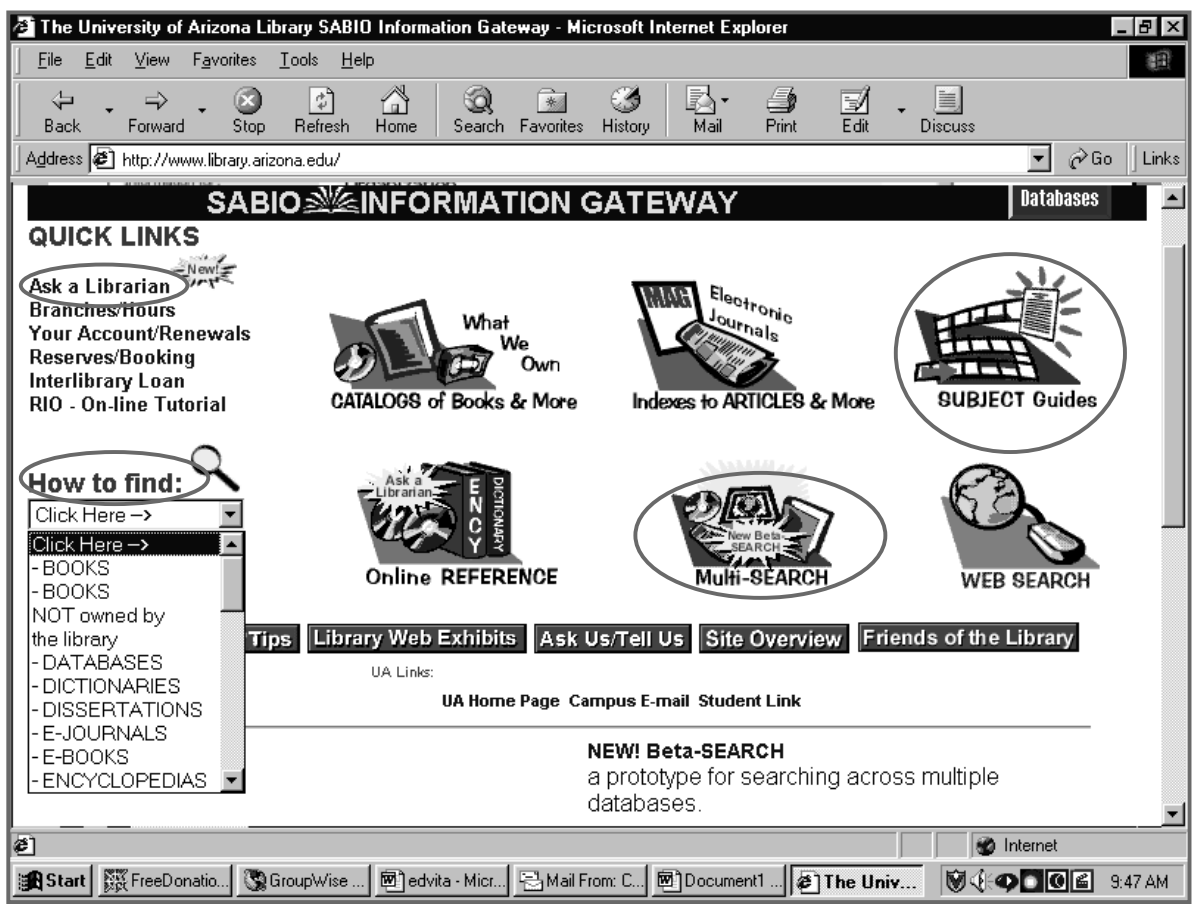

Figure 2: The University of Arizona Library's home page 


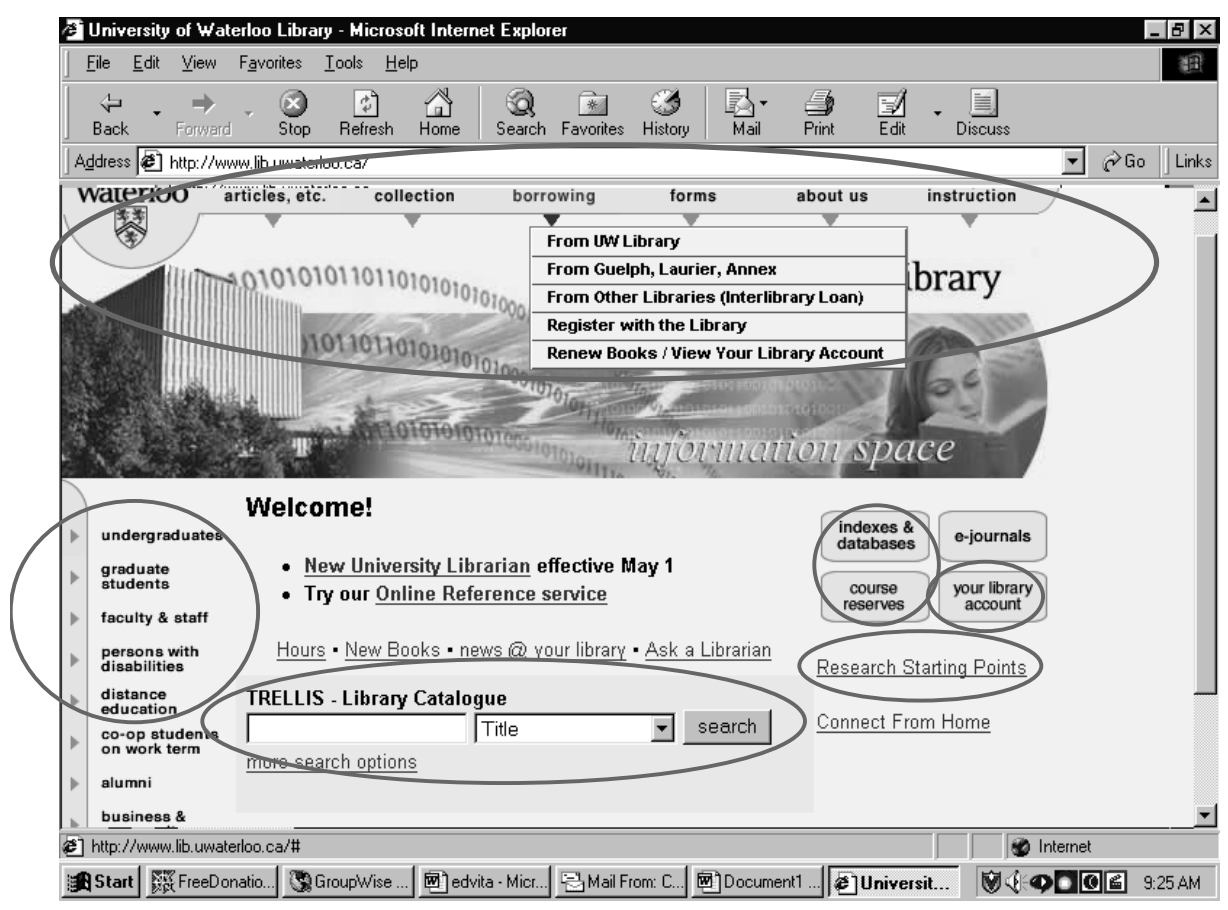

Figure 3: The University of Waterloo Library's home page 


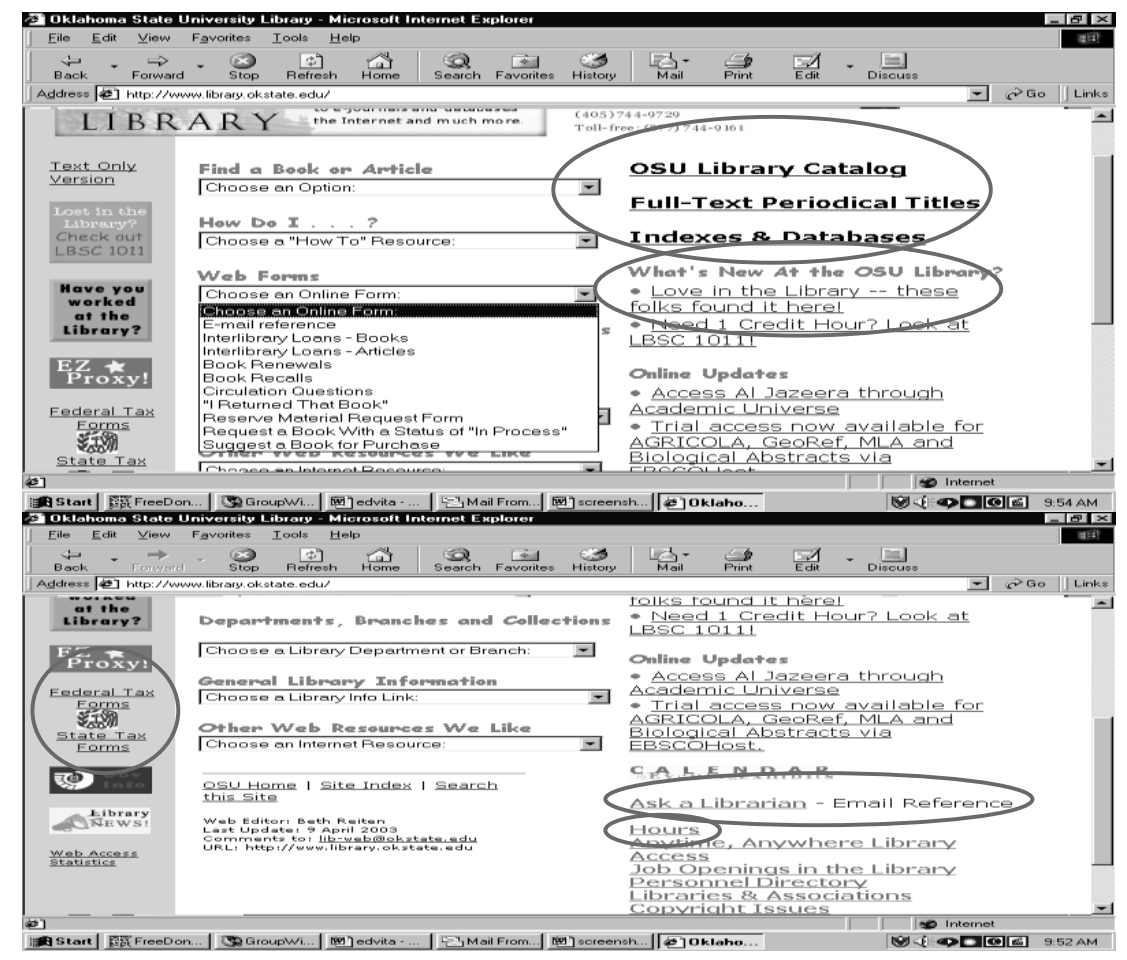

Figure 4: The home page for Oklahoma State Library 